\title{
Development a new method for pilot scale production of high grade oil palm plywood: effect of hot-pressing time
}

\begin{abstract}
The main objective in this study were to investigate the physical properties, mechanical properties and bonding qualities of oil palm stem (OPS) plywood pre-preg using low molecular weight phenolï formaldehyde (LmwPF). The properties evaluated were physical properties (resin uptake, weight percent gain), mechanical properties (bending strength) and bonding qualities (dry test, WPB test). The results showed that, the physical properties of OPS plywood were significant at resin concentration and veneer moisture content. Moreover, the mechanical properties and bonding performance of the pre-preg OPS plywood were influenced by the pressing time. The high grade OPS plywood with improved at least $227 \%$ MOR and $348 \%$ MOE compared to commercial OPS plywood, with greater in MOR $(31 \%)$ and MOE (12\%) higher compared than the commercial tropical mix light hardwood (MLHW) plywood. All the shear strength of pre-preg OPS plywood panel were achieved with their minimum requirements and satisfied all the specific testing based on the standard European Norms EN 314-1 and EN 314-2 for the interior and exterior application purposes. The output of this pilot scale study proved that high performance OPS plywood could produced through pre-preg enhancement method in the current plywood mills in which provides broader area of applications compared with conventional OPS plywood. For instant, the pre-preg OPS plywood which is suitable for structural application, concrete formwork, heavy duty interior structuring board, load bearing plywood, marine grade plywood, was obtained, thus consequently increases the price of OPS plywood panels.
\end{abstract}

Keyword: A. Natural materials; C. Surface treatments; E. Mechanical 